\title{
Assessment of Nutritional Status and Its Associated Factors in Elderly in Rural Area of Tamil Nadu, India
}

\author{
M. Vidyalakshmi ${ }^{1}$, B. Kirubhakaran ${ }^{2}$ \\ ${ }^{1}$ Senior Resident, Department of Geriatric Medicine, JIPMER, Pondicherry, India. \\ ${ }^{2}$ Assistant Surgeon, Government Hospital, Sivakasi, Tamil Nadu, India. \\ Corresponding Author: M.Vidyalakshmi
}

\begin{abstract}
Introduction: Ageing population is increasing rapidly in India, posing many challenges to health care services. One among the challenge is growing malnutrition in elderly. Malnutrition impairs body composition and body function of elderly thereby impairing their quality of life. Hence measures to prevent and treat malnutrition are need of the hour. Malnutrition is multifactorial and hence study to determine various factors associated with malnutrition becomes essential.
\end{abstract}

Aim and objective: The objective of present study was to assess the nutritional status of elderly and to study the various factors associated with malnutrition.

Materials and methods: Each individual in the study was subjected to a personal interview on demographic detail, living condition, literacy and financial status. Functional status was assessed using Instrumental activities of daily living (IADL), depression using Geriatric depression scale (GDS), nutritional status using Mini nutritional assessment (MNA) and caloric intake using 24 hour dietary recall.

Result: A significant association was found between the nutritional status and age group more than 75 years, female gender, illiteracy, living alone without family support, status of being financially and functionally dependent, depression and inadequate caloric intake.

Conclusion: It is essential to perform nutritional assessment as routine outpatient procedure for all elderly to detect malnutrition at earliest and intervene early to prevent deleterious effect of malnutrition on elderly. Multi dimensional approach is needed to educate about need of proper nutrition to elders and their caregivers.
Keywords: Caloric intake, Healthy ageing, Malnutrition, Nutrition

\section{INTRODUCTION}

The elderly population is extremely diverse, ranging from fit, active and healthy octogenarians to extremely frail, totally dependent people with chronic diseases and severe disabilities. The percentage of elderly is growing rapidly worldwide. The global number of elderly is projected to rise from an estimated 524 million in 2010 to 1500 million in 2050, with most of this increase in developing countries. ${ }^{[1]}$ India's geriatric population is also increasing rapidly accounting for $8.1 \%$ of total population and poses several challenges. ${ }^{[2]}$ The lack of guaranteed sufficient income to support themselves, the absence of social security, loss of social status and recognition, unavailability of opportunities for creative use of time and persistent ill health are some of the daunting problems the elderly face in this country. ${ }^{[3]}$ This increases the demand on care givers, the society and the health services of our country.

Malnutrition can be defined as the state of being poorly nourished, mostly lack of one or more nutrients. Malnutrition is not an inevitable side effect of ageing, but many changes associated with the process of ageing can promote malnutrition. It is a very frequent condition, especially in lower income group and institutionalized elderly people. In these subjects, malnutrition is the consequence of energy and protein deficiencies that cause adverse effects on 
body composition and on body function such as impaired muscle function, decreased bone mass, immune dysfunction, anaemia, reduced cognitive function, poor wound healing, delayed recovery from surgery, higher hospital admission and readmission rate and increased mortality. [4] The presence of malnutrition in hospitalised elderly may deeply affect the prognosis, the length of hospitalization, the incidence of acute events and complications. [5] Therefore the treatment and prevention of malnutrition in elderly, is an important challenge for the health care system.

While most nutritional intervention programs are directed toward infants, young children and pregnant mothers, nutrition and health of the elderly is often neglected. However, nutritional interventions could play a major role in the prevention of degenerative conditions of the elderly and can improve their quality of life. A timely intervention can stop weight loss in those at risk of malnutrition. An evaluation of nutritional status is important for the creation of database to assist in initiation of nutritional intervention programs and formulation of policies. Hence we conducted this study with an aim to assess the nutritional status of elderly and to study the various factors associated with malnutrition.

\section{MATERIALS AND METHODS}

A cross sectional study was conducted from April 2016 to September 2016 for a period of six months at Thiruverkadu, Thiruvallur district in Tamil Nadu. There were 440 community dwelling people, aged above 60 years in and around Thiruverkadu. People above 60 years who could understand and respond to questionnaires and willing to take part in the study were included in the study. Those who were seriously ill, fed by feeding tube and with known neuropsychiatric illness were excluded from the study. Based on inclusion and exclusion criteria, out of 440 elder people, only 386 people participated in the study. Institutional ethical committee approval was obtained and the study was carried out. Informed consent was taken from the participants before commencing the study.

Each individual in the study was subjected to a personal interview on demographic detail, living condition, literacy and financial status. Functional status was assessed using Instrumental activities of daily living (IADL), depression using Geriatric depression scale (GDS), nutritional status using Mini nutritional assessment (MNA) and caloric intake using 24 hour dietary recall.

A 24 hour dietary recall method was used to assess the caloric intake of the elderly. The calorie requirement was calculated by using Recommended Daily Allowance [RDA] 2010 guidelines as per the weight of the elderly. ${ }^{[6]}$

Nutritional status was assessed using Mini nutritional assessment (MNA) tool and the values were interpreted as follows: Score $<17$ was considered malnourished, Score 17-23.5 was considered at risk of malnutrition and Score >23.5 was considered well nourished. ${ }^{[7]}$ Weight and height were measured by using standardized weighing machine and stadiometer respectively. Weight was measured to the nearest $0.1 \mathrm{~kg}$ and height to the nearest 0.1 $\mathrm{cm}$. For the elderly with spinal curvatures, arm length was used to estimate height.

Elderly people who were selfearning, getting pension, having savings or getting rent for a house were considered financially independent. Functional status was assessed using Instrumental activities of daily living (IADL) using Lawton's index. ${ }^{[8]}$ Based on the self-reporting, the elderly who needed help with one or more item were assigned to the functionally dependent group. Geriatric depression scale (GDS) was used to assess depression in elderly. In Geriatric depression scale, a score of more than five indicated depression.

In order to find out the association of important variables with nutritional status, only those who fell into the categories of well-nourished and malnourished by MNA 
scoring were included. Those who fell into the "At risk" category were excluded. Analysis of qualitative variables was done using Chi-square test. Data thus collected was tabulated and chi-square test was used to determine the association of various factors with malnutrition. A $p$-value of less than 0.05 was considered to be statistically significant.

\section{RESULTS}

Table 1 summarizes the demographic details of the study population.

Table 1.Demographic detail of study population

\begin{tabular}{|l|l|l|l|}
\hline 1. & Age & 60-75 years & $278(72 \%)$ \\
\hline & & $76-85$ years & $96(24.8 \%)$ \\
\hline & & $>85$ years & $12(3.1 \%)$ \\
\hline $\mathbf{2 .}$ & Sex & Male & $218(56.4 \%)$ \\
\hline 3. & Living status & Wemale & $168(43.5 \%)$ \\
\hline & & With children & $54(13.9 \%)$ \\
\hline & & $\begin{array}{l}\text { With spouse and } \\
\text { children }\end{array}$ & $122(31.6 \%)$ \\
\hline & & With relative & $126.2 \%)$ \\
\hline & & Alone & $6(1.5 \%)$ \\
\hline $\mathbf{4 .}$ & Educational & Illiterate & $210(54.4 \%)$ \\
\hline & status & Upto primary school & $87(22.5 \%)$ \\
\hline & & Upto secondary school & $60(15.5 \%)$ \\
\hline & & College & $29(7.5 \%)$ \\
\hline $\mathbf{5 .}$ & Financial status & Independent & $142(36.7 \%)$ \\
\hline & & Dependent & $244(63,5 \%)$ \\
\hline
\end{tabular}

Using IADL, functional status was assessed showing 226 people as functionally independent and 160 people as functionally dependent. GDS showed 189 people as depressed and remaining 197 people were normal without depression.MNA showed 130 people as well nourished, 68 people as malnourished and 188 people at risk of malnutrition. Based on RDA guidelines of 2010, 230 people had adequate caloric intake and 156 people had inadequate caloric intake. Assessment details were summarized in Table 2.

Table 2.Assessment details of study population

\begin{tabular}{|c|c|c|c|}
\hline S.no & $\begin{array}{l}\text { Assessment } \\
\text { scale }\end{array}$ & Parameter & $\begin{array}{l}\text { Number } \\
\text { (percentage) }\end{array}$ \\
\hline \multirow[t]{2}{*}{1} & IADL & $\begin{array}{l}\text { Functionally } \\
\text { independent }\end{array}$ & $226(58.5 \%)$ \\
\hline & & $\begin{array}{l}\text { Functionally } \\
\text { dependent }\end{array}$ & $160(41.4 \%)$ \\
\hline \multirow[t]{2}{*}{2} & GDS & depressed & $189(48.9 \%)$ \\
\hline & & normal & $197(51.1 \%)$ \\
\hline \multirow[t]{3}{*}{3} & MNA tool & Well nourished & $130(33.6 \%)$ \\
\hline & & At risk & $188(48.7 \%)$ \\
\hline & & Malnourished & $68(17.6 \%)$ \\
\hline \multirow[t]{2}{*}{4} & RDA & $\begin{array}{l}\text { Adequate calorie } \\
\text { intake }\end{array}$ & $230(59.5 \%)$ \\
\hline & & $\begin{array}{l}\text { Inadequate } \\
\text { calorie intake }\end{array}$ & $156(40.4 \%)$ \\
\hline
\end{tabular}

A significant association was found between the nutritional status and age group more than 75 years, female gender, literacy, living status, status of being financially and functionally dependent, depression and inadequate caloric intake. It was found that malnutrition was significantly more prevalent in age more than 75 years, female gender and illiterate people. People living under the care of relatives or living alone were more malnourished. It was found that malnutrition was significantly present in people who were depressed, financially and functionally dependent on caregivers and those eat inadequate calories per day. Table 3 summarizes the association of different factors with malnutrition.

Table 3.Association of factors with malnutrition.

Table 3.Association of factors with malnutrition.
\begin{tabular}{|l|l|l|l|l|}
\hline S.no & Factor & Well nourished & Malnourished & P value \\
\hline 1 & Age $>75$ years & 14 & 28 & $<.00001$ \\
\hline 2 & Female & 52 & 44 & .0009 \\
\hline 3 & Living without spouse and children & 20 & 32 & .00015 \\
\hline 4 & Illiterate & 57 & 54 & $<.00001$ \\
\hline 5 & Financially dependent & 55 & 41 & .02 \\
\hline 6 & Functionally dependent & 47 & 37 & .013 \\
\hline 7 & Depressed & 60 & 44 & .017 \\
\hline 8 & Inadequate caloric intake & 53 & 44 & .0013 \\
\hline
\end{tabular}

Various reasons cited for inadequate caloric intake were problems of chewing and swallowing $(71.7 \%)$, some complained of loss of appetite(55.1\%), some indicated they could not afford it (67.9\%), for some, decisions regarding food intake was taken by caregivers $(56.4 \%)$ and $83.3 \%$ elderly were unaware of balanced diet. 


\section{DISCUSSION}

Like most geriatric problems, malnutrition is multifactorial and overlapping. Normal age-related changes in the neurological and musculoskeletal system were responsible for weakness in elderly individuals and this weakness is exacerbated by malnutrition. Prevalence of malnutrition in our study was $17.6 \%$ of elderly which was almost similar to result in studies by Vedantam et al ${ }^{[9]}$, Ferdous et al ${ }^{[10]}$, Baweja et al ${ }^{[11]}$, Saka et al ${ }^{[12]}$

In an attempt to study the association of different variables with malnutrition, it was found that older aged people were more malnourished. Similar relation of malnutrition with old age was found in studies by Baweja et al ${ }^{[11]}$ and Wadhwa et al ${ }^{[13]}$. Older people were less active and hence had a poor appetite leading to reduced calorie intake and malnutrition. Females were more malnourished in our study. This could be due to the role of women in the society and financial dependence. Studies by Saeidlou et al., ${ }^{[14]}$ Donini et al. ${ }^{[15]}$ and Boulos et al. ${ }^{[16]}$ also recorded significant association between female gender and malnutrition.

Other factors that contribute to malnutrition among the elderly are social isolation and financial deprivation. In our study, the percentage of malnutrition was significantly higher in those elderly who were living alone. This emphasizes the important role of social support for this age group, as they were often unable to serve themselves and have no support for preparing food.

The present study highlighted that higher educational status had the best nutritional status. Similar finding was also observed in other studies conducted in various parts of India and neighboring countries. ${ }^{[17,18,19]}$ This could be because of the fact that those with higher education might have better awareness about the nutritious food, healthy lifestyle and active aging.

Epidemiological studies have deeply analysed the relationship between poverty and nutritional status in the geriatric age and found that scarce economic resources limit the availability of access to food. Elderly people often have to decide what foods to give priority to purchase, with an increased risk of having a non- balanced diet in terms of macro- and micronutrients. Economic hardship can lead to the use of more energydense foods, that are less expensive, but with a lower nutritional quality. ${ }^{[20,21]}$

In our study there was a significant association of malnutrition with financial and functional dependence. This result was in accordance with other studies correlating malnutrition with financial status of the people ${ }^{[22,23]}$ and functional status of the people [24,25]. There was significant association between caloric intake and malnutrition in our study which was in accordance to the study by Vedantam et al [9] in South India.

Weight loss and malnutrition in elderly people due to poor dietary intake can also have psychological causes. Reality is often perceived by elderly people with a sense of futility. Elderly subjects usually are not able to succeed in their choices and to express their will, and they often direct their aggression against themselves. The first manifestation of depression is the lack of interest in food. ${ }^{[26,27]}$ In our sample, depression was very frequent and seemed to be related to nutritional status.

This study had some limitations. No assessment of biochemical parameters of nutritional status and hemoglobin were done. It was also not possible to look into morbidities which might affect nutritional status.

\section{CONCLUSION}

As there is significant proportion of geriatric people with malnutrition and risk of malnutrition, it is necessary to raise awareness of the elderly and their caregivers about the quality, quantity and frequency of food intake. However, a multidimensional approach is required at this moment to deal with these issues. Routine screening for malnutrition is essential for early detection 
and prompt treatment, and should be an integral part of the regular geriatric outpatients to increase the quality of care and optimize outcomes. Supportive interventions like encouraging communal eating, providing meals on wheels are also beneficial.

\section{REFERENCES}

1. National Institute on Aging, National Institutes of Health. United States: NIH Publication; 2011. Global Health and Ageing.

2. Registrar General of India, Government of India. India: 2011. Census of India.

3. Panigrahi AK. Determinants of Living Arrangements of Elderly in Orissa: An Analysis: Working Paper 2009. Bangalore: The Institute for Social and Economic Change; 2009.

4. Stratton rJ, Green cJ, elia M.Disease related Malnutrition: an evidence based approach to treatment oxford: cabi; 2003.

5. Lattanzio F, Laino i, Pedone c, corica F, Maltese G, Salerno G, Garasto S, corsonello a, incalzi ra; on behalf of the Pharmacosurveillance in the elderly care (Pvc) Study Group:: Geriatric conditions and adverse Drug reactions in elderly Hospitalized Patients. am Med Dir assoc. 2011 May 27

6. A Report of the Expert Group of the Indian Council of Medical Research, NIN. ICMR; 2009. Nutrient Requirements and Recommended Dietary Allowances for Indians.

7. Mini Nutritional Assessment. Nestle Nutrition Institute.

8. Graf C. The Lawton Instrumental Activities of Daily Living (IADL) Scale, Hartford Institute for Geriatric Nursing, New York University, College of Nursing. Revised 2007; (Issue Number 23)

9. Vedantam A, Subramanian V, Rao NV, John KR. Malnutrition in free-living elderly in rural south India: Prevalence and risk factors. Public Health Nutr. 2010;13:132832.

10. Ferdous T, Kabir ZN, Wahlin A, Streatfield $\mathrm{K}$, Cederholm T. The multidimensional background of malnutrition among rural older individuals in Bangladesh - A challenge for the Millennium Development Goal. Public Health Nutr. 2009;12:2270-8.
11. Baweja S, Agarwal H, Mathur A, Haldiya KR, Mathur A. Assessment of nutritional status and related risk factors in community dwelling elderly in western Rajasthan. J Indian Acad Geriatr. 2008;1:5-13.

12. Saka B, Kaya O, Ozturk GB, Erten N, Karan MA. Malnutrition in the elderly and its relationship with other geriatric syndromes. Clin Nutr. 2010;29:745-8.

13. Wadhwa A, Sabharwal M, Sharma S. Nutritional status of the elderly. Indian J Med Res. 1997;106:340-8.

14. Saeidlou SN, Merdol TK, Mikaili P, Bektas Y. Assessment of the nutritional status and affecting factors of elderly people living at six nursing home in Urmia, Iran. Part I. Int J Acad Res. 2011;3:1.

15. Donini LM, Scardella P, Piombo L, Neri B, Asprino R, Proietti AR, et al. Malnutrition in elderly: Social and economic determinants. J Nutr Health Aging. 2013; 17:9-15.

16. Boulos C, Salameh P, Barberger-Gateau P. The AMEL study, a cross sectional population-based survey on aging and malnutrition in 1200 elderly Lebanese living in rural settings: Protocol and sample characteristics. BMC Public Health. 2013; 12(13):573.

17. Shivraj M, Singh VB, Meena BL, Singh K, Neelam M, Sharma D, et al. Study of nutritional status in elderly in Indian population. IJCR. 2014;6(11):10253-57.

18. Lahiri S, Biswas A, Santra S, Lahiri SK. Assessment of nutritional status among elderly population in the rural areas of West Bengal, India. Int J Med Sci Public Health. 2015;4(4):569-72.

19. Ghimire S, Baral BK, Callahan K. Nutritional assessment of communitydwelling older adults in rural Nepal. PLoS ONE. 2017;12(2).

20. Sun LJ, Frongillo, ea. nutritional and health consequences are associated with food insecurity among uS elderly persons. J nutr 2001; 131:1503-9;

21. Wolfe, WS, Frongillo, ea, valois, P. understanding the experience of food insecurity by elders suggests ways to improve its measurement. J nutr 2003; 133: 2762-9;

22. Saikia A, Mahanta N. A study on nutritional status of elderly in terms of body mass index in Urban Slums of Guwahati City. J Indian Acad Geriatr. 2013;9:11-4. 
23. Han Y, Li S, Zheng Y. Predictors of nutritional status among communitydwelling older adults in Wuhan, China. Public Health Nutr. 2009;12:1189-96.

24. Shahar S, Ibrahim Z, Fatah AR, Rahman SA, Yusoff NA, Arshad F, et al. A multidimensional assessment of nutritional and health status of rural elderly Malays. Asia Pac J Clin Nutr. 2007;16:346-53.

25. Oliveira MR, Fogaça KC, Leandro-Merhi VA. Nutritional status and functional capacity of hospitalized elderly. Nutr J. 2009;17(8):54.

26. German L, Kahana c, rosenfeld v, Zabrowsky i, Wiezer Z, Fraser D, Shahar Dr.: Depressive symptoms are associated with food insufficiency and nutritional deficiencies in poor community-dwelling elderly people. J nutr Health aging. 2011; 15(1):3-8).

27. Mokhber N, Majdi M, Ali-Abadi M, Shakeri M, Kimiagar M, Salek R, et al. Association between Malnutrition and Depression in Elderly People in Razavi Khorasan: A Population Based-Study in Iran. Iran J Public Health. 2011;40:67-74.

How to cite this article: Vidyalakshmi M, Kirubhakaran B. Assessment of nutritional status and its associated factors in elderly in rural area of Tamil Nadu, India. Gal Int J Health Sci Res. 2021; 6(1): 38-43. 